\title{
Experienced pain after stroke: a cross- sectional 5-year follow-up study
}

\author{
Emma Westerlind, Ramanjit Singh, Hanna C. Persson ${ }^{* \dagger}$ (ID and Katharina S. Sunnerhagen ${ }^{\dagger}$
}

\begin{abstract}
Background: Stroke is one of the most common cause of disability worldwide. Pain is common in both stroke survivors and in the general population. Consequences of post-stroke pain (PSP) include reduced quality of life and are important to consider. The aim of the current study was to explore the experience of pain 5 years after stroke, and factors associated with the experience of pain.

Methods: Inclusion criteria were: First ever stroke, treated at Sahlgrenska University Hospital, Sweden, during an 18 months period in 2009-2010, aged 18 years or older. Furthermore, the participants had to respond to a set of questionnaires 5 years post-stroke. Baseline data were collected from medical records and follow-up data from the set of questionnaires. The primary outcome was based on the question Do you experience pain? Predictors and explanatory factors for experiencing more frequent pain were analysed with logistic regression.

Results: A total of 281 participants were included. Almost 40\% experienced pain to some degree 5 years poststroke (15\% reported pain frequently), and $25 \%$ felt that their needs for pain treatment were not met. The participants experiencing more frequent pain reported poorer quality of life, self-perceived health status and recovery post-stroke. Functional dependency at discharge from hospital, experiencing depression at follow up and restricted mobility at follow up were all associated with more frequent pain.

Conclusion: Pain is common 5 years post-stroke and the treatment is not perceived as optimal. The persons experiencing more frequent pain seem to rate their health and recovery worse than the persons experiencing less frequent pain. Most of the factors associated with more frequent pain were treatable and this emphasize the importance of standardised follow-up care that takes pain into consideration.
\end{abstract}

Keywords: Stroke, Pain, Quality of life, Follow-up

\section{Background}

Stroke is the second most common cause of death [1], though due to improved preventative health care and an ageing population the number of people surviving a stroke is increasing [2]. The growing population of stroke survivors may experience a variety of complications such as depression, physical disability, cognitive impairment and post-stroke pain (PSP) [3].

The prevalence of pain as reported in research varies, but a large study in the US showed that more than $50 \%$ of a general population had experienced pain the last 3

\footnotetext{
* Correspondence: hanna.persson@neuro.gu.se

${ }^{\dagger}$ Hanna C. Persson and Katharina S. Sunnerhagen contributed equally to this work.

Department of Clinical Neuroscience, Institute of Neuroscience and Physiology, University of Gothenburg, Per Dubbsgatan 14, 41345 Gothenburg, Sweden
}

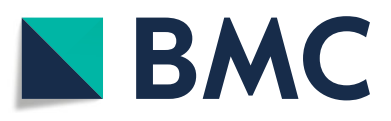

(c) The Author(s). 2020 Open Access This article is distributed under the terms of the Creative Commons Attribution 4.0 International License (http://creativecommons.org/licenses/by/4.0/), which permits unrestricted use, distribution, and reproduction in any medium, provided you give appropriate credit to the original author(s) and the source, provide a link to the Creative Commons license, and indicate if changes were made. The Creative Commons Public Domain Dedication waiver (http://creativecommons.org/publicdomain/zero/1.0/) applies to the data made available in this article, unless otherwise stated. ity of life [5], reduced capacity to take part in daily activities [6], interference with occupation [7] and depressive disorders [8].

Pain as a consequence after stroke has a prevalence of $11-66 \%$ [9]. However, pain is not always directly correlated to stroke and data from several studies suggest that PSP is more common in patients with pain prior to the stroke $[10,11]$. There are several different types of PSP such as headache, shoulder pain, pain due to muscle stiffness, spasm, complex regional pain syndrome and central PSP [12-14]. This may also include experience of pain and presence of sensory abnormalities in body parts affected by the cerebrovascular lesion [12].

A review study presented that risk factors of PSP included female sex, older age, alcohol use, and depression 
[9]. Furthermore, stroke-related risk factors of PSP included ischemic stroke, spasticity, reduced upper extremity movement and sensory deficits [9].

Most previous studies have focused on specific types of pain and few have investigated the prevalence of any type of PSP [15]. Furthermore, the time to pain assessment after stroke varies in previous research, but followup more than 2 years post-stroke is uncommon $[9,16]$. PSP affects daily living [17] and can be an obstacle to rehabilitation [18]. Additional research is therefore of great importance in order to provide the optimal health-care for the effected individuals.

The aim of the current study was to explore experience of pain 5 years after stroke, and factors associated with the experience of pain.

\section{Methods}

\section{Study design and participants}

This cross-sectional follow-up study was based on data from the Stroke Arm Longitudinal study at the University of Gothenburg (SALGOT)-extended [19-21]. During 18 months between February 2009 and December 2010 all patients admitted to a stroke unit, neurosurgical ward or intensive care unit at Sahlgrenska University Hospital in Gothenburg, Sweden, were eligible for the SALGOT-extended study. The inclusion criteria were: first-ever ischemic stroke (IS) (I63), intracerebral haemorrhage (ICH) (I61) or subarachnoid haemorrhage (SAH) (I60) diagnosis; resident in the Gothenburg urban area (within $35 \mathrm{~km}$ from the Sahlgrenska University Hospital); be 18 years old or older at stroke onset. The Sahlgrenska University Hospital is the single centre in the area that provides interventions such as thrombectomy and thrombolysis.

Data from the acute phase was collected from medical records. Five years post-stroke, the survivors received a postal survey (including two reminders) consisting of a set of questionnaires focusing on the long-term consequences of stroke. The set of questionnaires included a follow-up questionnaire from Riksstroke, EuroQol Quality of life scale (EQ5D) and the Stroke Impact Scale (SIS).

\section{Clinical assessments}

At arrival to hospital, stroke severity was (in the case of IS or ICH) assessed with National Institutes of Health Stroke Scale (NIHSS) 0-46 [22] and in patients with confirmed SAH with Hunt and Hess $(\mathrm{H} \& \mathrm{H}) 1-5$, where a lower score suggests a less clinically severe presentation [23]. The NIHSS total score was divided into the following groups: very mild (0-2), mild (3-4), moderate (5-15) and severe (16-46). At discharge from hospital, the functional dependency was assessed with the modified Rankin Scale (mRS) 0-5 [24]. The mRS was dichotomized in the current study into: functionally independent if score $0-2$ and functionally dependent if score 3-5 [25]. From medical records at stroke onset, two chronic pain-related comorbidity variables were collected; musculoskeletal disorders and all possible painrelated disorders. Musculoskeletal disorders included for instance; neck pain, arthrosis, and rheumatoid arthritis. Pain-related conditions included all the musculoskeletal disorders as well as conditions such as migraine, angina pectoris, and cancer.

\section{Questionnaire follow-up}

From the Riksstroke questionnaire, the questions what is your level of mobility, do you feel depressed, do you experience pain, and have your needs of treatment for pain been met were used. The question about depression was dichotomized into experiencing depression (answering often or always) or not (answering never/almost never or sometimes). The level of mobility was dichotomized into intact mobility (answering: mobile indoors and outdoors without assistance) and restricted mobility (needing assistance outdoors or always needing assistance). The experience of pain was dichotomized into experiencing less pain (answering never/almost never or sometimes) and experiencing more pain (answering often or always).

The EQ5D [26] was used to measure health-related quality of life. The EQ5D includes questions relating to the following domains; mobility, self-care, usual activities, pain/discomfort and anxiety/depression. Each of the questions can be answered as no problem, some problem or extreme problem. In addition to this, a visual analogue scale (VAS) estimate the respondents selfperceived health ranging from 0 to 100 (higher score corresponds to less self-perceived health problems).

The stroke Impact Scale (SIS) $[27,28]$ is used to measure post-stroke recovery. In the present study, a VAS was used to provide an estimate of the respondents' recovery ranging from 0 to 100 (higher score is better) were used.

\section{Statistical analysis}

All analyses were carried out using the IBM SPSS version 23. Significance level was set at $p<0.05$. Differences between groups were analysed with Fischer's exact test and Mann Whitney U test.

Logistic regression was used to investigate predictors and explanatory factors for experiencing more pain. Two separate regression models, one predictive and one explanatory, were built. Dependent variable in both models were the dichotomized experience of pain. Independent variables in the predictive model were: age at stroke onset, sex, the dichotomized functional dependency at discharge, existence of musculoskeletal disorders, and existence of all possible pain-related disorders. Independent variables in 
the explanatory model were: age at time of follow-up, sex, the dichotomized functional dependency at discharge, existence of musculoskeletal disorders and existence of all possible pain-related disorders, the dichotomized level of mobility and the dichotomized experience of depression.

In the model building procedure, an adequate sample size was first ensured. Multicollinearity between independent variables was investigated using Spearman's correlation test with correlation coefficients $< \pm$ 0.7 being acceptable for inclusion in the regression model. Univariate logistic regressions were performed for each independent variable with a $p$-value $<0.25$ considered acceptable for inclusion in the multivariable model. In the multivariable analysis, backward stepwise selection was used with the significance level set at $p<0.05$. Finally, variables excluded in univariate analysis were re-inserted to the final model one by one to and included if statistically significant. The goodness of fit and the accuracy of the multivariable regression models were evaluated with Hosmer and Lemeshow Test, the Nagelkerke $\mathrm{R}$ square and a $\mathrm{Re}$ ceiver Operating Characteristic (ROC) curve [29]. An area under the ROC curve $>0.70$ indicate acceptable accuracy.

\section{Results}

As seen in Fig. 1, of the 457 persons that received the mail survey, 281 participants responded. There was no significant difference between respondents and nonrespondents regarding level of functional dependency at discharge from hospital or in age. However, differences were seen regarding sex, the non-respondents consist of more women than men $(p=0.001)$.

The mean age at stroke onset was 65 years and $61 \%$ of the participants were men (Table 1). Less than $7 \%$ of the participants were dependent in personal activities of daily living (ADL) and approximately 25\% were dependent in instrumental ADL five years post-stroke.

\section{Experienced pain}

Of the 271 patients who answered the question do you experience pain 19 (7\%) reported always having pain, 23 (9\%) often, 66 (24\%) sometimes, and 163 (60\%) never/almost never. Dichotomized, this gives 15\% (42 persons) that reported more frequent pain and $85 \%$ (229 persons) that reported less frequent pain. Participants who reported having more frequent pain also reported experienced depression ( $p$-value <0.001) and restricted mobility $(\mathrm{p}$-value $=0.002)$ compared to participants who

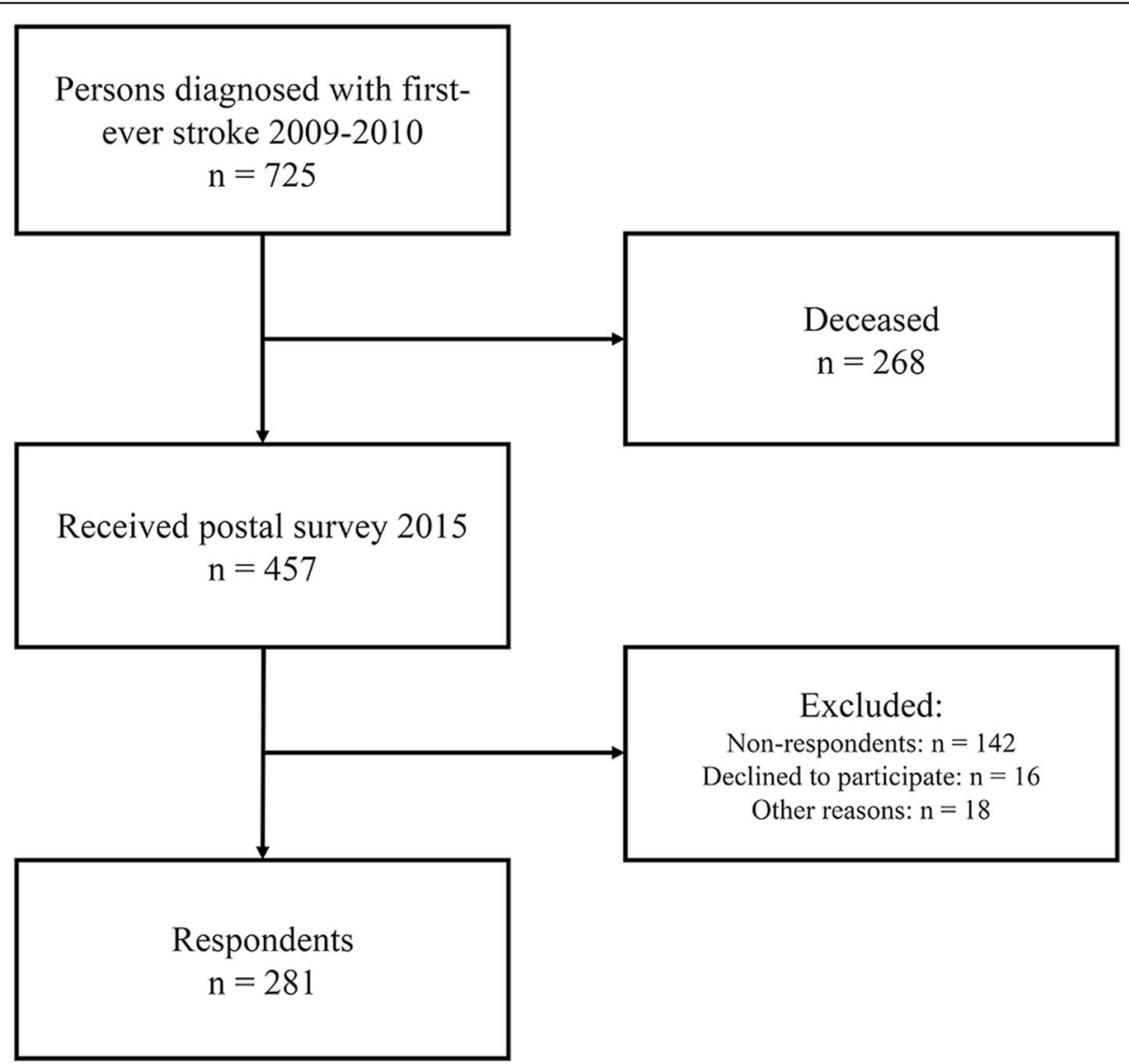

Fig. 1 Flowchart of the inclusion of the participants 
Table 1 The participants characteristics at stroke onset and at five years post-stroke $(n=281)$

\begin{tabular}{|c|c|}
\hline \multicolumn{2}{|l|}{ Demographics } \\
\hline Age at time of stroke onset, mean (SD) & $65.4(13.5)$ \\
\hline \multicolumn{2}{|l|}{ Sex, n (\%) } \\
\hline Male & $171(60.9)$ \\
\hline Female & $110(39.1)$ \\
\hline \multicolumn{2}{|l|}{ Stroke type, n (\%) } \\
\hline IS & $218(77.6)$ \\
\hline $\mathrm{ICH}$ & $36(12.8)$ \\
\hline $\mathrm{SAH}$ & $27(9.6)$ \\
\hline \multicolumn{2}{|l|}{ NIHSS at stroke onset, $\mathrm{n}(\%), n=230$} \\
\hline Very mild (0-2) & $144(62.6)$ \\
\hline Mild (3-4) & $25(10.9)$ \\
\hline Moderate (5-15) & $46(20.0)$ \\
\hline Severe (16-46) & $15(6.5)$ \\
\hline Median (min-max) & $1(0-24)$ \\
\hline \multicolumn{2}{|l|}{$\mathrm{H} \& \mathrm{H}, \mathrm{n}(\%), n=27$} \\
\hline Grade 1 & $4(14.8)$ \\
\hline Grade 2 & $14(51.9)$ \\
\hline Grade 3 & $2(7.4)$ \\
\hline Grade 4 & $4(14.8)$ \\
\hline Grade 5 & $1(3.7)$ \\
\hline Unknown & $2(7.4)$ \\
\hline \multicolumn{2}{|l|}{ Comorbidity, $\mathrm{n}(\%), n=276$} \\
\hline Musculoskeletal disorder & $36(13.0)$ \\
\hline Pain-related disorders & $76(27.5)$ \\
\hline
\end{tabular}

Characteristics five years post-stroke

Do you receive help with eating/drinking? $\mathrm{n}(\%) n=277$

Yes 4 (1.4)

Do you receive help going to the bathroom? $\mathrm{n}(\%) n=279$ Yes

Do you receive help getting dressed? $\mathrm{n}(\%), n=278$ Yes

Do you receive help with grocery shopping? $\mathrm{n}(\%), n=279$ Yes

Do you receive help with cleaning? $\mathrm{n}(\%), n=279$ Yes

What is your level of mobility? $\mathrm{n}(\%), n=279$

Intact mobility

Restricted mobility

Do you feel depressed? $\mathrm{n}(\%), n=270$

Experiencing depression

Not experiencing depression

$232(85.9)$
Table 1 The participants characteristics at stroke onset and at five years post-stroke $(n=281)$ (Continued)

\begin{tabular}{|c|c|}
\hline \multicolumn{2}{|l|}{ Do you feel pain? $\mathrm{n}(\%), n=271$} \\
\hline Experiencing more pain & $42(15.5)$ \\
\hline Experiencing less pain & $229(84.5)$ \\
\hline $\begin{array}{l}\text { Self-perceived recovery post-stroke (SIS), median (min- } \\
\text { max), } n=261\end{array}$ & $80(0-100)$ \\
\hline $\begin{array}{l}\text { Self-perceived health status post-stroke (EQ VAS), median } \\
\text { (min-max), } n=254\end{array}$ & $80(10-100)$ \\
\hline
\end{tabular}

had less frequent pain. Furthermore, participants that were functional dependent at discharge also reported more frequent pain $(\mathrm{p}$ - value $=0.018)$. There were no statistically significant differences between the groups of participants with more or less frequent pain regarding age at stroke onset, sex, comorbidity, living conditions or prior history of stroke. Participants with more frequent pain scored their self-perceived health status and recovery post-stroke significantly lower (median value 50 and 55 respectively) in comparison with participants with less frequent pain (median value 80 and 85 respectively), $p$-value $<0.001$.

The EQ5D domains compared between the pain groups are presented in Fig. 2. More frequent pain was associated with poorer outcome in all five domains ( $p$-value $<0.001)$.

Of the 269 participants responding to the question about pain treatment, $64 \%$ reported having no need for pain treatment, $11 \%$ were fully satisfied with their treatment while 19 and $6 \%$ reported that their needs were only partially or not at all met respectively. There were no significant differences between participants with fulfilled needs and those not satisfied with received treatment regarding sex, age, comorbidity.

\section{Factors associated with pain}

The participants that were functionally dependent at discharge from hospital, compared to the functionally independent had higher odds of experiencing more frequent pain 5 years post-stroke (OR 2.413) in the predictor model (Table 2). Age, musculoskeletal disorders and pain-related disorders did not fulfil statistical criteria, and were not included in the model. Of the included factors, sex did not contribute significantly to the final model.

The results from the explanatory multivariable regression analysis are presented in Table 3. Age, musculoskeletal disorders and pain-related disorders were excluded prior to the final regression model due to unfulfilled statistical criteria, and sex and level of functional dependency did not make a significant contribution to the model. Having restricted mobility (OR 3.649) and 


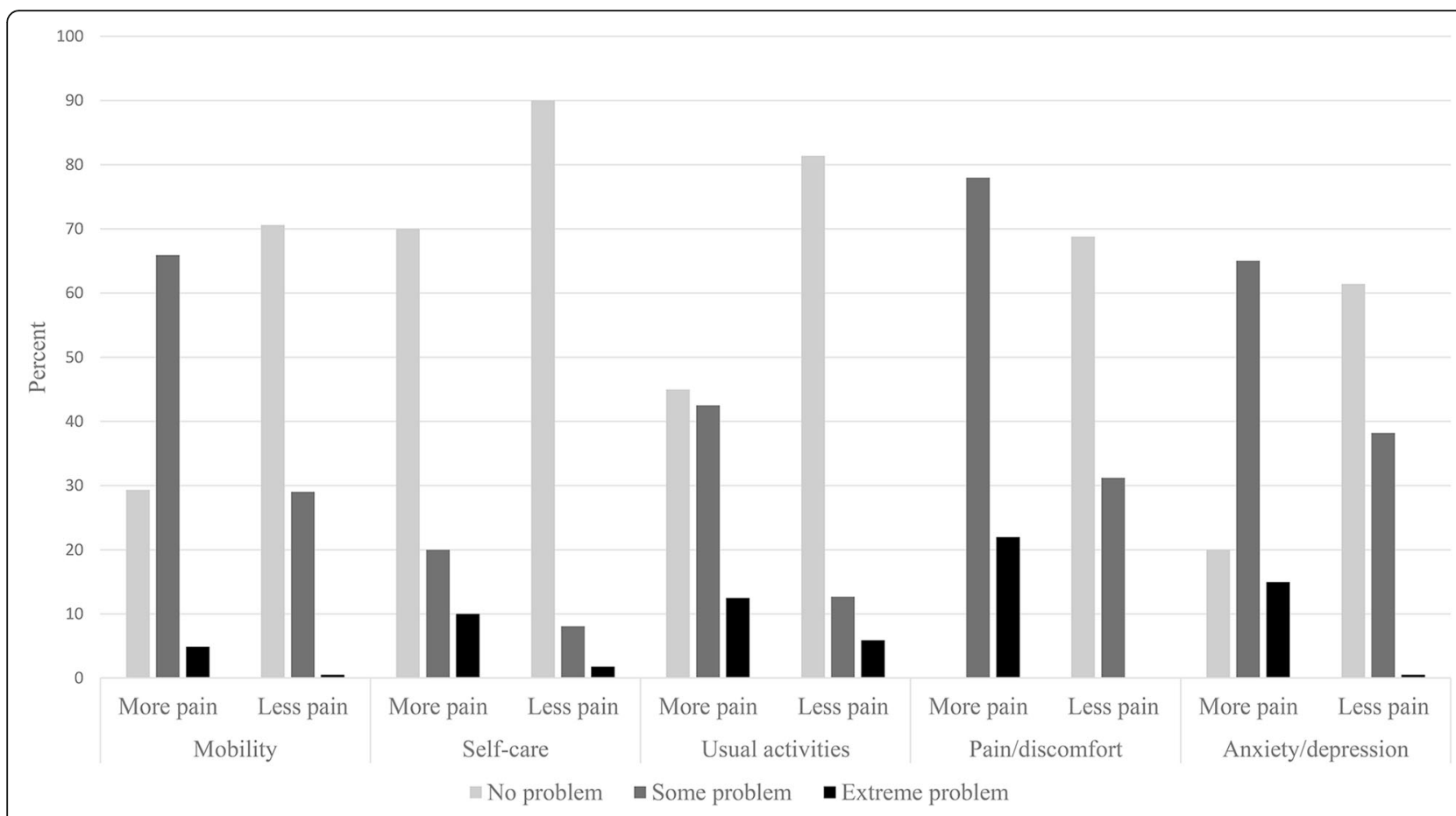

Fig. 2 Health-related quality of life in the EQ5D domains, compared between the 2 pain groups

experiencing depression (OR 7.953) were significant explanatory factors for more frequent pain.

\section{Discussion}

The majority of participants (85\%) in the present study did not experience frequent pain five years after stroke and most of the participants (64\%) did not feel that they needed treatment for pain. The participants who were functionally dependent at discharge, who reported experience of depression or were restricted in their mobility had higher odds of experiencing pain frequently. Additionally, participants with more frequent pain scored their health status and recovery post-stroke significantly lower and had a poorer health-related quality of life, compared to participants who experienced less frequent pain.

Approximately $40 \%$ of the participants in the current study experienced pain to some degree (including more frequent pain as well as sometimes having pain). This is in line with findings in a previous study from Denmark [13]. A previous study in a general Swedish population reported a higher prevalence of pain, $51 \%$

Table 2 Significant predictors of post-stroke pain in multivariable analysis

\begin{tabular}{lclc}
\hline Predictor variables & $P$-value & OR & $95 \%$ C.I. for OR \\
\hline Functionally dependent & 0.014 & 2.413 & $1.194-4.878$ \\
\hline
\end{tabular}

Area under the ROC-curve 0.60. Nagelkerke R Square 0.041. Abbreviations: OR: odds ratio; C.l: confidence interval
[30]. The prevalence of pain both in stroke survivors and the general population has varied greatly in previous research $[9,31]$. Pain is a subjective feeling and the definition of pain may vary between different individuals. Furthermore, assessing pain is difficult. For instance the wording of the questions asked may considerably influence the outcome. Several studies specifically asked about pain that started after stroke and/or pain that the participants themselves relate to their stroke $[10,13,15,32]$. Such a distinction between pain related to stroke and pain not related to stroke has been described with a prevalence of stroke-related pain of $11 \%$ [32]. This distinction of pain was not possible in the present study, due to the design of the questionnaire, which could explain the higher prevalence of pain found in the present study.

In the explanatory regression model, restricted mobility and experienced depression were found to be significant contributors to the experience of pain. Participants who experienced depression had almost 8-fold higher odds of experiencing more frequent pain. This is in line with previous research where depression has been noted to be a significant explanatory variable for pain both in individuals with stroke $[13,33]$ and individuals with no prior history of stroke $[15,34]$. However, the causal relationship between depression and pain remains unclear [35]. According to one review article, approximately one in three persons suffer from depression at some point post-stroke with the highest prevalence during the first 
Table 3 Significant explanatory variables of post-stroke pain in multivariable analysis

\begin{tabular}{llll}
\hline Explanatory variables & $P$-value & OR & $95 \%$ C.I. for OR \\
\hline Restricted mobility & 0.009 & 3.649 & $1.390-9.574$ \\
Experience depression & $<0.001$ & 7.953 & $3.593-17.602$ \\
\hline
\end{tabular}

Area under the ROC-curve 0.708. The Hosmer and Lemeshow test: $p$-value 0.613. Nagelkerke R Square 0,211. Abbreviations: OR Odds ratio, C.I Confidence interval

year [36]. Five years post-stroke, one in five individuals fulfil the diagnostic criteria for depression [37]. In the present study, the results are based on the subjective experience of feeling depressed, which is not the same as an objective assessment or a diagnosis of clinical depression. This could explain the overall high prevalence (52\%) of depression found in the current study. Participants with restricted mobility had almost 4-fold higher odds of experiencing more frequent pain (as seen in the explanatory model). Mobility restriction can be a direct consequence of stroke. Motor impairments affect approximately $80 \%$ of all stroke patients [38], and have been significantly associated with PSP [15]. Furthermore, a consequence of pain could be physical inactivity, and it could be speculated that immobility itself can cause pain, also seen in the present study. In addition to adequate pharmacological treatment, an individualized physical exercise program may therefore be an important part in pain management. Regular physical activity has been shown to decrease the intensity of pain, improve independence in activities of daily living, decrease depressive symptoms and improve range of joint movement [39, 40]. The final explanatory regression model explained $21 \%$ of the variance in the outcome which implies there are other variables not used in the present study that contribute to the experience of pain. Lower socioeconomic status, habits such as smoking and absence of personal support are all variables that have been identified as risk factors for pain in previous research and were not considered in the present study [41].

In the predictive regression model, participants that were functionally dependent at discharge had higher odds of experiencing more frequent pain 5 years poststroke. This is in line with the results of mobility being an explanatory factor for pain, since the functional dependency scale has a substantial mobility component. However, the final model had a low rate of variance explained in the outcome and a low accuracy. Consequently, functional dependency at discharge cannot solely be used to predict who may experience more frequent pain 5 years post-stroke. These results highlight the complex nature of the pain experience and support there being multiple contributing factors in PSP. As shown previously, both demographical, premorbid and stroke-related factors have been associated with PSP [9].
In the present study, one in four participants reported unmet needs for pain treatment and 6\% reported that their needs were not addressed at all. The lack of pain treatment is not only seen in the stroke population but in the general population as well. In one large-scale European study, approximately one third of the participants with chronic pain were not receiving any treatment for their chronic pain [12]. In the same study, one in five Swedish respondents reported that their current medication was inadequate in pain relief [12]. These findings highlight the need for standardized follow-up, for instance the post-stroke checklist [42], after stroke where pain is considered.

Participants who experienced more frequent pain scored their self-perceived health status and recovery post stroke significantly lower compared to the participants who experienced less frequent pain. Furthermore, more frequent pain was associated with poorer healthrelated quality of life. These findings further emphasise the importance of considering pain in follow-up care of all persons with stroke.

\section{Limitations}

The generalisability of the results in the present study has some limitations. The study setting is in persons with stroke in Sweden and the social situation may not reflect the rest of the world. The study design was study based on mail-survey from a single centre cohort, lacking a control group. An age matched control group would have added information and improved the implications of the results. The majority of the participants suffered a milder stroke, which needs to be taken into account when generalizing the findings. Higher stroke severity has been associated with pain in previous research [32]. The mean age at stroke onset was 65 years which is lower than in the general Swedish stroke population. Older age has been found to be a significant explanatory variable for pain in previous research [43], which therefore could affect the generalisability of the present results.

Another limitation of the present study is that a distinction between stroke-related pain and pain not related to stroke was not possible. A questionnaire specific dedicated to distinguish different types of pain would have been beneficial for the study. However, the aim of the study was to explore experienced pain 5 years poststroke in general, not only stroke-related pain.

The response rate was $61 \%$ in the present study. This means that $39 \%$ did not respond to the postal survey, which needs to be considered. Drop out-analysis was carried out and significantly more women were found in the non-responding group, thus yielding a study population with more men. Women overall tend to report 
more pain, potentially leading to a lower frequency of pain in the present study.

\section{Conclusion}

Pain is common five years post-stroke, almost $40 \%$ of the participants reported pain of varying frequency. More frequent pain was associated with poorer quality of life and lower self-perceived health status and recovery post-stroke. Furthermore, participants who were functionally dependent at discharge, who experienced depression or were restricted in their mobility had higher odds of experiencing more frequent pain. The present study also found that one in four participants had unmet needs for pain treatment. These results emphasize the need of standardized follow-up care after stroke where persons with stroke are actively asked about pain and given appropriate treatment.

\section{Abbreviations \\ EQ5D: EuroQol quality of life scale; H\&H: Hunt \& hess; ICH: Intracerebral haemorrhage; IS: Ischemic stroke; mRS: Modified rankin scale; NIHSS: National institutes of health stroke scale; PSP: Post-stroke pain; SAH: Subarachnoid haemorrhage; SALGOT: Stroke arm longitudinal study at the university of Gothenburg; SIS: Stroke impact scale; VAS: Visual analogue scale}

\section{Acknowledgements}

We would like to thank Dr. Kate Bramley-Moore for proofreading and English language assistance.

\section{Authors contributions}

EW, RS, HCP, and KSS all made contributions to conception and design. HCP and KSS acquired the data. HCP and KSS obtained funding. RS analysed and interpreted the data. EW and RS wrote the draft and the revisions of the manuscript, and HCP and KSS commented and critically reviewed the manuscript drafts and revisions. All authors read and approved the final manuscript.

\section{Funding}

This work was supported by the Swedish Science Council (VR2017-00946), the Swedish Heart and Lung foundation, the Swedish Brain foundation, Promobilia, the Norrbacka Eugenia foundation and the Swedish state under the agreement between the Swedish government and the county councils, the ALF agreement (ALFGBG-718711). Open access funding provided by University of Gothenburg.

\section{Availability of data and materials}

The datasets analysed during the current study are not publicly available due to ethical restrictions. According to the Swedish regulation http://www.epn. se/en/start/regulations/ the permission to use data is only for what has been applied for and then approved by the Ethical board. Data are available from the authors (contact Professor Katharina S. Sunnerhagen, email: ks. sunnerhagen@neuro.gu.se) upon reasonable request.

\section{Ethics approval and consent to participate}

The SALGOT study was approved by the regional ethical review board in Gothenburg (Dnr 225-08 and T801-10) and followed the Helsinki declaration. The follow-up postal survey was approved in 2013 (Dnr 400-13). The data in the present study is anonymized and non-identifiable. No written or verbal consent were obtained, but information was given about the purpose of the follow-up postal survey and that participation was voluntary. Participants could choose to answer all or some of the questions.

\section{Consent for publication}

Not applicable.

\section{Competing interests}

The authors declare that they have no competing interests.

Received: 10 July 2019 Accepted: 22 December 2019

Published online: 07 January 2020

\section{References}

1. Lozano R, Naghavi M, Foreman K, Lim S, Shibuya K, Aboyans V, Abraham J, Adair T, Aggarwal R, Ahn SY, et al. Global and regional mortality from 235 causes of death for 20 age groups in 1990 and 2010: a systematic analysis for the global burden of disease study 2010. Lancet. 2012;380(9859):2095-128.

2. Feigin VL, Krishnamurthi RV, Parmar P, Norrving B, Mensah GA, Bennett DA, Barker-Collo S, Moran AE, Sacco RL, Truelsen T, et al. Update on the global burden of ischemic and hemorrhagic stroke in 1990-2013: the GBD 2013 study. Neuroepidemiology. 2015;45(3):161-76.

3. Maaijwee NA, Rutten-Jacobs LC, Schaapsmeerders P, van Dijk EJ, de Leeuw FE. Ischaemic stroke in young adults: risk factors and long-term consequences. Nat Rev Neurol. 2014;10(6):315-25.

4. Nahin RL. Estimates of pain prevalence and severity in adults: United States, 2012. J Pain. 2015;16(8):769-80.

5. Skevington SM. Investigating the relationship between pain and discomfort and quality of life, using the WHOQOL. Pain. 1998;76(3):395-406.

6. Breivik H, Collett B, Ventafridda V, Cohen R, Gallacher D. Survey of chronic pain in Europe: prevalence, impact on daily life, and treatment. Eur J Pain. 2006:10(4):287-333.

7. Azevedo LF, Costa-Pereira A, Mendonca L, Dias CC, Castro-Lopes JM. Epidemiology of chronic pain: a population-based nationwide study on its prevalence, characteristics and associated disability in Portugal. J Pain. 2012; 13(8):773-83.

8. Gureje O, Von Korff M, Simon GE, Gater R. Persistent pain and well-being: a World Health Organization study in primary care. JAMA. 1998;280(2):147-51.

9. Harrison RA, Field TS. Post stroke pain: identification, assessment, and therapy. Cerebrovasc Dis. 2015;39(3-4):190-201.

10. Jonsson AC, Lindgren I, Hallstrom B, Norrving B, Lindgren A. Prevalence and intensity of pain after stroke: a population based study focusing on patients perspectives. J Neurol Neurosurg Psychiatry. 2006;77(5):590-5.

11. Hansen AP, Marcussen NS, Klit H, Andersen G, Finnerup NB, Jensen TS. Pain following stroke: a prospective study. Eur J Pain. 2012;16(8):1128-36.

12. Klit H, Finnerup NB, Jensen TS. Central post-stroke pain: clinical characteristics, pathophysiology, and management. Lancet Neurol. 2009;8(9):857-68.

13. Klit H, Finnerup NB, Overvad K, Andersen G, Jensen TS. Pain following stroke: a population-based follow-up study. PLoS One. 2011;6(11):e27607.

14. Delpont B, Blanc C, Osseby GV, Hervieu-Begue M, Giroud M, Bejot Y. Pain after stroke: a review. Rev Neurol (Paris). 2018;174(10):671-4.

15. Lundstrom E, Smits A, Terent A, Borg J. Risk factors for stroke-related pain 1 year after first-ever stroke. Eur J Neurol. 2009;16(2):188-93.

16. Widar M, Samuelsson L, Karlsson-Tivenius S, Ahlstrom G. Long-term pain conditions after a stroke. J Rehabil Med. 2002;34(4):165-70.

17. Widar M, Ek AC, Ahlstrom G. Coping with long-term pain after a stroke. J Pain Symptom Manag. 2004;27(3):215-25.

18. Chae J, Yu D, Walker M. Percutaneous, intramuscular neuromuscular electrical stimulation for the treatment of shoulder subluxation and pain in chronic hemiplegia: a case report. Am J Phys Med Rehabil. 2001;80(4):296-301.

19. Persson HC, Parziali M, Danielsson A, Sunnerhagen KS. Outcome and upper extremity function within 72 hours after first occasion of stroke in an unselected population at a stroke unit. Part SALGOT Study BMC Neurol. 2012;12:162

20. Vikholmen K, Persson HC, Sunnerhagen KS. Stroke treated at a neurosurgica ward: a cohort study. Acta Neurol Scand. 2015;132(5):329-36.

21. Wesali S, Persson HC, Cederin B, Sunnerhagen KS. Improved survival after non-traumatic subarachnoid haemorrhage with structured care pathways and modern intensive care. Clin Neurol Neurosurg. 2015;138:52-8.

22. Brott T, Adams HP Jr, Olinger CP, Marler JR, Barsan WG, Biller J, Spilker J, Holleran $R$, Eberle $R$, Hertzberg $V$, et al. Measurements of acute cerebral infarction: a clinical examination scale. Stroke. 1989;20(7):864-70.

23. Hunt WE, Hess RM. Surgical risk as related to time of intervention in the repair of intracranial aneurysms. J Neurosurg. 1968;28(1):14-20.

24. van Swieten JC, Koudstaal PJ, Visser MC, Schouten HJ, van Gijn J. Interobserver agreement for the assessment of handicap in stroke patients. Stroke. 1988;19(5):604-7. 
25. Sulter G, Steen C, De Keyser J. Use of the Barthel index and modified Rankin scale in acute stroke trials. Stroke. 1999;30(8):1538-41.

26. Rabin R, de Charro F. EQ-5D: a measure of health status from the EuroQol group. Ann Med. 2001;33(5):337-43.

27. Duncan PW, Bode RK, Min Lai S, Perera S. Rasch analysis of a new strokespecific outcome scale: the stroke impact scale. Arch Phys Med Rehabil. 2003;84(7):950-63.

28. Duncan PW, Wallace D, Lai SM, Johnson D, Embretson S, Laster L. The stroke impact scale version 2.0. Evaluation of reliability, validity, and sensitivity to change. Stroke. 1999;30(10):2131-40.

29. Field A: Discovering statistics using IBM SPSS statistics : and sex and drugs and rock ' $n$ ' roll, 4. edn. Los Angeles London: Sage; 2013.

30. Dragioti E, Larsson B, Bernfort L, Levin LA, Gerdle B. Prevalence of different pain categories based on pain spreading on the bodies of older adults in Sweden: a descriptive-level and multilevel association with demographics, comorbidities, medications, and certain lifestyle factors (PainS65+). J Pain Res. 2016;9:1131-41.

31. Fayaz A, Croft P, Langford RM, Donaldson LI, Jones GT. Prevalence of chronic pain in the UK: a systematic review and meta-analysis of population studies. BMJ Open. 2016;6(6):e010364.

32. Appelros P. Prevalence and predictors of pain and fatigue after stroke: a population-based study. Int J Rehabil Res. 2006;29(4):329-33.

33. Hansen AP, Marcussen NS, Klit H, Kasch H, Jensen TS, Finnerup NB. Development of persistent headache following stroke: a 3-year follow-up. Cephalalgia. 2015;35(5):399-409.

34. McWilliams LA, Cox BJ, Enns MW. Mood and anxiety disorders associated with chronic pain: an examination in a nationally representative sample. Pain. 2003;106(1-2):127-33.

35. Magni G, Moreschi C, Rigatti-Luchini S, Merskey H. Prospective study on the relationship between depressive symptoms and chronic musculoskeletal pain. Pain. 1994;56(3):289-97.

36. Towfighi A, Ovbiagele B, El Husseini N, Hackett ML, Jorge RE, Kissela BM, Mitchell PH, Skolarus LE, Whooley MA, Williams LS. Poststroke depression: a scientific statement for healthcare professionals from the American Heart Association/American Stroke Association. Stroke. 2017;48(2):e30-43.

37. Hackett ML, Pickles K. Part I: frequency of depression after stroke: an updated systematic review and meta-analysis of observational studies. Int J Stroke. 2014;9(8):1017-25.

38. Langhorne P, Coupar F, Pollock A. Motor recovery after stroke: a systematic review. Lancet Neurol. 2009;8(8):741-54.

39. Tse MM, Tang SK, Wan VT, Vong SK. The effectiveness of physical exercise training in pain, mobility, and psychological well-being of older persons living in nursing homes. Pain Manag Nurs. 2014;15(4):778-88.

40. Eng JJ, Reime B. Exercise for depressive symptoms in stroke patients: a systematic review and meta-analysis. Clin Rehabil. 2014;28(8):731-9.

41. Bergman S, Herrstrom P, Hogstrom K, Petersson IF, Svensson B, Jacobsson LT. Chronic musculoskeletal pain, prevalence rates, and sociodemographic associations in a Swedish population study. J Rheumatol. 2001;28(6):1369-77.

42. Philp I, Brainin M, Walker MF, Ward AB, Gillard P, Shields AL, Norrving B. Global stroke community advisory P: development of a poststroke checklist to standardize follow-up care for stroke survivors. J Stroke Cerebrovasc Dis. 2013;22(7):e173-80.

43. Eriksen J, Jensen MK, Sjogren P, Ekholm O, Rasmussen NK. Epidemiology of chronic non-malignant pain in Denmark. Pain. 2003;106(3):221-8.

\section{Publisher's Note}

Springer Nature remains neutral with regard to jurisdictional claims in published maps and institutional affiliations.

Ready to submit your research? Choose BMC and benefit from:
- fast, convenient online submission
- thorough peer review by experienced researchers in your field
- rapid publication on acceptance
- support for research data, including large and complex data types
- gold Open Access which fosters wider collaboration and increased citations
- maximum visibility for your research: over 100M website views per year
At BMC, research is always in progress.
Learn more biomedcentral.com/submissions

